2016-01-07

\title{
Student geographies and homemaking: personal belonging(s) and identities
}

Holton, Mark

http://hdl.handle.net/10026.1/4973

10.1080/14649365.2015.1126626

Social and Cultural Geography

Informa UK Limited

All content in PEARL is protected by copyright law. Author manuscripts are made available in accordance with publisher policies. Please cite only the published version using the details provided on the item record or document. In the absence of an open licence (e.g. Creative Commons), permissions for further reuse of content should be sought from the publisher or author. 


\title{
Student geographies and homemaking: personal belonging(s) and identities
}

\author{
Abstract \\ Studies of the 'geographies of students' have become increasingly prevalent across the social \\ sciences and are particularly concerned with the predilection for young UK University \\ undergraduates to be mobile in their institutional choice. A more recent focus within this \\ work has been upon student identities, with attention given to how the spaces in which \\ students move to and settle in can have both positive and negative consequences for the \\ evolution of the student identity, and how such identities are often framed within the context \\ of social activities; learning environments; friendship networks or other socio-cultural \\ factors. This paper contributes to these discussions by considering the role of student \\ accommodation - a site which often remains on the periphery of discussions of student \\ identities - in offering students opportunities to construct, adapt and manage their student \\ identities. This adds to the important contemporary geographies of student accommodation \\ which are currently debating, among others, purpose-built student accommodation and the \\ broad housing 'careers' and strategies of students. In contrast, this paper explores the micro- \\ geographies of student accommodation (and more specifically, the bedroom) to highlight its \\ value in providing young, mobile students with an anchor within which they can draw \\ together their learner, social and domestic dispositions into one geographical location.
}

\section{Keywords}

Student geographies; identity; place; home; material belongings; student mobility

\section{Introduction}


Studies of the 'geographies of students' (after Smith 2009) have become increasingly prevalent across the social sciences, with particular consideration given to the mobility and dispersion of UK higher education (HE) students. As Smith et al. (2014) have recently noted, geographers are becoming increasingly aware that spaces of education act as: "prominent anchors, essential markers of social and cultural identity and training grounds for the future social and spatial mobilities in the lives and aspirations of many young people” (5) meaning the spaces in which students interact (homes, classrooms, social spaces etc.) may directly inform their University experiences. A popular focus within this work has been upon student identities, with attention given to how the spaces in which students move to and settle in can have both positive and negative consequences for the evolution of the student identity (Chow and Healey 2008; Fincher and Shaw 2009), and how such identities are often framed within the context of social activities (Chatterton 1999); learning environments (Reay et al., 2010); friendship networks (Brooks 2003) or other socio-cultural factors (Andersson et al., 2012). This paper furthers this discussion through a consideration of the role of student accommodation - a site which often remains on the periphery of discussions of student identities - and how this may offer students opportunities to learn to construct, adapt and manage their student identities. There has been no shortage of work recognising the important geographies of student accommodation, with interesting debates opening up, for example, around purpose-built student accommodation (e.g. Smith and Hubbard 2014) and also that seeking to chart the broad housing 'careers' and strategies of students (Christie et al., 2002; Rugg et al., 2004). This paper, by contrast, takes a more micro-scale approach to bring together these two areas of concern by exploring the role student accommodation (and more specifically, the bedroom) plays in the (re)development of students's subject positions during the course of their degree. 
While there has been ample discussion of the physical configuration of student accommodation (Amole 2009; Thomsen 2007; Fincher and Shaw 2009), less attention has been given to its role in the development of a sense of place. This omission may seem surprising given the attention, within the critical geographies of home literature, to the importance of living spaces as a place of identity expression (Blunt and Varley 2004; Blunt 2005; Brickell 2012; Morrison, 2013). Several reasons might be postulated for this. First, such an omission may, in part, be due to the way that the discussion(s) on place-making have focussed on homemaking as a longer-term process rather than as something more transitory - often only one to two years in the case of students' term time experiences (although see Waitt and Gorman-Murray 2011). Second, the uniformity (in material terms) of halls of residence (hereafter halls) means that they do not, perhaps, stand out as immediately obvious spaces for the study of homemaking. Thirdly, the discussion of student's 'yo-yo' tendencies between term-time and 'permanent' residences mean that home, for them, may be multiplysited and difficult to define.

This paper brings together the literatures emanating from what might be termed the 'geographies of students' and that from the critical geographies of home in order to better understand the complexities faced by undergraduate students of 'making' place in a period of complex (and periodical) transition. The paper explores these themes by: (1) examining the ways in which students position their belongings taken from home within their term-time bedrooms to act as bridges between their familial and temporary homes; (2) highlighting how the introduction of artefacts bought during term-time can complicate and suppress their prestudent identities and; (3) considering the processes of self-archiving which can be employed as students attempt to 'round off' their student identities as they prepare to leave University and return to the family home or beyond. In doing so, the paper contributes to the broader 
discussion of 'homemaking' practices and the role of everyday living environments within the construction and performance of identities.

\section{Situating home and belonging(s)}

In attempting to understand the complexities of how students view, enact and reproduce their 'student' identities within their term-time accommodation it is first necessary to frame what is meant by the term 'home'. There is an abundant literature which articulates how the home is imbued with meanings connected to identity, belonging and lived experience (Blunt 2005; Blunt and Varley 2004; Walsh 2006b). However, Gorman-Murray (2007) argues that our representations of home are at once contrasting and contested, discursive and imaginative, and drawing upon Blunt and Dowling (2006) he highlights the contradictory power relations which may exist within the home which amplify and/or suppress certain social relations according to the ideologies of those involved. Crucially then, the home is a place in which a variety of social and spatial practices are carried out, from intimacy, closeness and desire, to isolation, brutality and fear (Blunt 2005). Hence, the embodiment of the home is highly influential in establishing a 'sense of place'. Although the definition of 'home' may be highly elastic and multi-scalar - being used in the discussion of 'the household' through to the 'nation' and beyond (Holdsworth and Morgan 2005) - we use, here, the definition of home as both a physical, material, space as well as a place of meaning to emphasise how much work goes in to making a 'house' a 'home'. Gorman-Murray (2006; 2008) highlights the complexity of this process by noting home is a place where both public and private identities become situated. He talks of how processes, such as 'queering' the home in his specific example, may be essential in the identity affirmation of gay men, particularly as the ways in which such homes are constructed and used may deviate from the home as being a recognisably 'heteronormative' space. Therefore, exploring the domestic experiences of those 
in transition, rather than focusing upon the broader flows of transience itself, will provide a more accurate representation of home in a mobile sense (Dunn 2010).

Important to recent discussions of the home, and in framing our discussion of student rooms, is the consideration of material culture and belongings. Two theoretical trajectories can be traced within this discussion - that based in semiotics which pays attention to what objects might signify and/or represent in social discourses, and that from cultural geography and cultural anthropology which attends to the ways people use objects and how these objects are embedded in social relations. As Woodward (2001) notes, these should not be seen as mutually exclusive, or antagonistic, analytical frameworks. Stemming from the criticalsemiotics of Roland Barthes (1993), work in this vein highlights how an object may, on the one hand, have a use value and on the other hand act as signifiers - be that of prestige, status, beauty or difference. Adding to the consideration of the semiotic capacity of objects has been work considering their affective qualities. In the context of the home work from within geography, sociology and anthropology has looked in particular at the role material possessions play in the construction of subjectivities (e.g. Miller 2008; Morrison 2013). Research in this area has begun to recognise the ways that belongings and possessions "give material support to the identity of those whose home it is” (Young 2005: 140). Young (2005), for example, points to the process of 'integration and remembrance' whereby material possessions, particularly those passed from previous generations can bring together narratives of the past and present into a more coherent narrative of the self. As Hecht (2001: 123) concurs, the way we keep and arrange belongings "binds our past with our present and possible futures, thereby framing and reflecting our sense of self”. Belongings can also have a transitional value and this has been shown in a range of empirical contexts and may have both a spatial and temporal element. Temporally, work such as that by Hockey et al (2005) with older adults facing the death of a long-term partner show how possessions and the 
material arrangement of the home can perform important 'emotional mediation' as they “embody the past in the present” and mediate an ongoing social relationship with those now deceased. Spatially, Blunt and Dowling (2006) show how a wide range of material possessions and are used to (re)make home for diasporic and transnational communities, and Marcoux (2001) suggests that individuals moving home take objects which symbolise the self. Linking these together, Tolia-Kelly (2004: 676) shows how the material cultures which frame the "new textures of home" for South Asian diaspora living in London are "shot through with the memory of 'other' spaces of being” with photographs and mementoes both acting as a reminder of home, but also reaffirming a sense of enfranchisement and belonging in their new, less exclusionary, home context. In other contexts, this idea of personal possessions as inducing reminiscence has been applied to gerontological studies which have seen how belongings can have a therapeutic value and enhance morale in later life, and how the value of possessions changes over the lifecourse and periods of transition (Rowles and Chadbury 2005). Environmental psychologists have similarly noted how objects in the home may be deployed in the maintenance of self-esteem and have considered the instrumental and emotional comforts that they may afford (Borg et al, 2005).

The significance and meaning of objects may be reworked over time and studies have noted that this is a complex layered process. Gorman-Murray’s (2008) and Peters’ (2011) research, for example, illustrate how home possessions may be used to materially reflect the 'whole self' - with belongings comprising a range of connections with cultural heritage, family and travels for example. Crucially, Gorman-Murray (2008) notes that this conjoining of objects and identities has a history and these material objects which make up the 'whole self' do not come about instantly but are collected over time meaning each one has a different level of attachment. Just as the collection and display of belongings are identity forming, so too may be acts of disposal. Gregson et al. (2007a) suggest disposal is intrinsically part of the self, 
whereby the object for disposal holds its own narrative and the resultant 'throwing away' constitutes a rounding off, or completion of that narrative: "harmonising the relation between self and the co-present object world of consumer goods in our homes” (689). Walsh (2006b) identifies a level of pragmatism in particular acts of disposal, in which the individual divorces themselves from the relative value of the material item, whilst Hollows (2008) argues that certain items refuse to be discarded, suggesting a degree of agency can be present in belongings. However, Gregson et al.’s (2007b) study highlights the need to view disposal in a more holistic context stressing that divestment, while being constitutive of a form of normativity, may also be about making way for other consumption practices. In extending this discussion of disinvestment into the context of mobility and migration Walsh (2006b) notes how practices of discarding and disowning may be constitutive acts, where a self "is able to create home in mobility without the use of domestic props” (272) as the temporal and spatial narratives of belongings do not necessarily easily translate from one location to another.

In taking forward the discussion of the affective relationships between people, place and things Morrison (2013) has noted how homes and the objects within them are not only important for the performance and demarcation of individual subject positions, but also facilitate shared and collective subjectivities. Whilst this has been explored within the discussion of the homes of homosexual couples (see Gorman-Murray, 2006), Morrison (2013) calls for similar attention to joint and collective homemaking practices within heterosexual partnerships. She notes how, for example, artefacts such as couple photographs and wedding pictures are not only material expressions of a shared experience; they also serve to reproduce specific gendered (and sexed) subjectivities in relation to domestic space. Through considering the positioning and use of artefacts such as DVDs, pictures and 'his' and 'hers' razors, Morrison (2013) highlights how heterosexuality and home become 
mutually reproduced through everyday practices and how these practices may "congeal over time to produce the appearance of 'normal' gendered articulations of heterosexual home space” (p. 423). Important to note from Morrison’s (2013) research is that although these belongings and household goods materialise shared subjectivities, they may run concurrently with other objects being used to maintain individuality within shared domestic spaces - an insight which is important to this paper where students commonly live in 'shared' accommodation such as halls of residence or collectively rented private housing.

This recognition of the dynamism of home - such as being at once a public and private space and a space of both individuality and collectivity - is important for conceptually framing the consideration of students, especially those in the UK context considered here, where their living arrangements are commonly away from home, finite in duration and involve different levels of cohabitation. So too the recognition that domestic objects serve multiple and shifting purposes necessitates an application of both semiotic and cultural approaches to understanding these - recognising that objects may be used both as a signifier (perhaps of style or status) or in performing roles in the management of self-esteem and self-identity and also in the making of connections to other people, places and times.

\section{Geographies of youthful and student homes}

Alongside the literature on possessions and home more generally are those studies focusing specifically on themes of home and transition amongst students and young[er] people. The young may appear to follow a fairly linear trajectory from the dependence of childhood, through to the semi-dependence of youth and finally into the messier in[ter]dependence of adolescence. While this may often be expressed through material resources (particularly if the child has some form of income), in emotional and social terms, adolescents often strive for interdependence. The term interdependence is preferred here as young house sharers often 
seek a lifestyle associated with cohabitation rather than the complete autonomy of living alone (Lahelma and Gordon 2008). In relation to the micro-geographies of the home Steele and Brown (1995) argue that youth bedrooms represent spaces within which to experiment with 'possible selves'. Positive markers, such as the potential for privacy, room size and quantity of belongings promote a greater sense of place attachment for young people (Fidzani and Read 2012). In contrast, Larson (1995) suggests a correlation between self-imposed solitude and increased levels of negativity among adolescents. However, rather than being adverse, this relationship can be seen as "providing valuable personal opportunities for emotional self-regulation and cultivation of the private self” (541).

Extending these discussions to ‘student geographies’ (after Smith 2009) reveals a link between mobility and accommodation and student living. Within the UK, the vast majority of undergraduate students will leave home in order to spend a period of time residing in termtime accommodation (Duke-Williams 2009). Importantly, for first year students, this often involves a year living in a University managed halls, a site which often represents a more sheltered transition away from home. Decisions to leave home for University are not flippant or casual choices. As Lahelma and Gordon (2003) suggest:

"Home is a space that consists of physical places, social practices, and mental meanings for young people. All the aspects are evoked when they plan or dream about moving away from their parental home” (377).

The transition into student accommodation has been seen to be constructed in relation to that of the familial home meaning prospective students must commonly negotiate their preexisting identities, routines and behaviours within an often shared environment (Kenyon 1999). As Chow and Healey (2008) suggest, this may result in a process of cross-referencing between the two with students continually drawing comparisons between term-time accommodation and the family home until they establish some form of place attachment. 
Kenyon (1999) moves on to suggest that experiences of the family home and the student home will inform how young adults wish to experience future homes, yet it is unclear as to whether these desires ever become realities. The UK student experience of living away from home has for many, therefore, become a defining feature of attending University. As Holdsworth (2009a: 227) proposes: "being a student is emblematic for not being from around here”. Despite this observation, it is important to note that even in the UK - the context of this paper - the 'student experience' is far from universal with students approaching University through various trajectories (Holton and Riley 2013) and recent developments such as the increasing trend towards choosing institutions near to, or a commutable distance away from the family home in order to remain 'local' (Christie 2007).

\section{Methodology}

The data for this research is drawn from a project investigating how undergraduate students at the University of Portsmouth establish a 'sense of place' whilst in their term-time University location ${ }^{1}$. A mixed method approach was utilised, incorporating a survey, interviews and participant photography to collect data for the project - the latter two of which are drawn upon specifically in this paper. 31 interviews were conducted with University of Portsmouth undergraduates between January and May 2012. These participants were recruited through a web-based survey in which they were asked to accompany the researcher on a walking tour of the city which culminated in a sit down face-to-face discussion of their

\footnotetext{
${ }^{1}$ The UK's only island city, Portsmouth covers approximately $40 \mathrm{~km}_{2}$ and has a population of 197,614 with a population density of, on average 5000 people per square kilometre, making it the UK's most densely populated city by area outside of London (Portsmouth City Council (PCC) 2012). Portsmouth also has a large youth population with a third (33.6 percent) under the age of 25, three per cent higher than the national average of 30.7 percent (PCC 2012) which reflects Portsmouth's large student population. The University of Portsmouth currently has 22,709 students as of 2012-13 constituting approximately eleven percent of the city's population. This is comprised of: 18,878 ( 83 percent) full time and 3,831 (17 percent) part time students, with 18,889 (83 percent) undergraduates and 3,217 (17 percent) postgraduates (University of Portsmouth 2012).
} 
student accommodation ${ }^{2}$. The students interested in taking part were sent an email providing the details of the research. Some inevitably withdrew, often because the walking aspect required greater involvement than a conventional interview. Nevertheless, a strong and diverse selection of participants were drawn together which provided a good range of responses. Given that those interviewed often shared accommodation with other housemates or family members - thus making consent and permission for participation difficult - it was decided not to conduct the interviews in student accommodation, but instead use photographs (after Rose 2007) of student living spaces as a way of interpreting how they utilise the communal and private rooms within this accommodation. No instructions were given to the students as to what was to be included in these photographs and they were asked to supply them prior to the interview so that they could be referred to during the discussion. This was useful as it fitted with the inclusive themes of place-based interviews being beneficial in eliciting experiences to environments rather than simply gaining responses to questions (Housley and Smith 2010). Importantly, utilising these images moved beyond simple visual prompts. Being able to encourage the participants to talk about these images allowed us greater opportunities to (1) get an idea of the context of how they used their bedrooms, particularly as there were great contrasts in the visual appearance of them (see Figures 1 and $2)^{3}$; (2) engage in a dialogue with the participants to visually and orally interpret the material and affective significance of their belongings and (3) encourage the participants to be critical of these spaces through deeper reflection and self-analysis. Moreover, the tense in which the participants spoke about these images during the analysis was important here. They referred to them in the present, as if they were tangible, adding to the notion that photographs are powerful analytical tools which are capable of drawing the past into the present. Therefore,

\footnotetext{
${ }^{2}$ For more details on the 'walking interviews' see: Holton and Riley (2014).

${ }^{3}$ In order to maintain anonymity photographs visible from the pictures have been blurred.
} 
while the researcher was not party to the taking of these images, their interpretive (and to a certain extent comparative) qualities were more than useful during the interview process. Of course, it would be naive to assume that these photographs did not carry their own agency (Rose 2007). As they have been produced by the participants themselves, it is difficult to consider them as entirely 'natural' scenes as they may have been staged in order to expose or hide particular details. Rather than viewing objects in the home as inherent and fixed, therefore, the paper develops a similar recognition to Hurdley (2006: 717) that their meaning is contingent and "co-constructed by informant, researcher and objects within their domestic setting”. As she observes, the construction of narratives around these objects - that is, those that we elicit within the interviews discussed later - is in itself a work of identity-building.

In all, 21 of the interview participants had resided in shared student accommodation at some point during their degree. This comprised nine students in their first year, five in their second year and seven in their third year of study. This study group was composed of eight male and thirteen female participants, the majority of which were under 21 years of age (only Lorna ${ }^{4}$, Sophia, Robert and Lyndsey were classed as mature students) and were predominantly white (18) and British (18). As an aside, while the 'walking' aspect of the interview process is not alluded to in the analysis for this paper, what rather serendipitously emerged from utilising a mobile interviewing technique was that the relaxed nature of the walk - the rhythmic pace, lack of eye contact and constant environmental stimulus (see Riley 2010; Holton and Riley 2014) meant that the participants regularly steered the conversations on to their residential experiences, particularly their relationships with housemates and their homemaking activities. The interviews were audio recorded and transcribed and coded using the computer aided qualitative data analysis software (CAQDAS) package Atlas-ti. These themes were then

\footnotetext{
${ }^{4}$ All names have been anonymised.
} 
analysed using a grounded theory technique to tease out theories through an iterative process of careful coding and sorting.

\section{Setting out, Setting up and Fitting in}

In being invited to talk about the arrangement of belongings within their bedrooms a point that soon became apparent across the interviews was that whilst the bedroom in the familial home may be imagined, and commonly narrated, as a 'private' space for identity expression, student rooms take on a on a more hybrid existence - being at once 'front stage' and 'backstage' (Goffman 1959). ${ }^{5}$ The interview with Dan illustrates this fluidity, with an early extract from his interview positioning student rooms as somewhere where one could relax and shut themselves away:

“I just shut the door, I mean if you're doing work, you know, we consider each other's space because we know that we have work to do all the time” (Dan, Y1).

But later in the same interview he refers to how the bedroom was also somewhere to hangout with housemates:

“We play mini football in my mate’s room because he’s got the biggest room. If we stayed in our rooms it would just be awkward you know?” (Dan, Y1).

This observation of the dual nature of bedrooms is important in contextualising the way that objects were selected for, and arranged within, these rooms. At one level, the discussion of the possessions revealed that belongings provided a link to homes and alleviated

\footnotetext{
${ }^{5}$ It should be noted that even though homes may be talked of in this dualistic way, "the domestic is created through the extra-domestic and vice versa” (Blunt and Dowling, 2006: 27). Although not specifically referred to by any of the students interviewed here, a good example of how such a challenge to the idea of the bedroom as a space of privacy was the introduction of the 'bedroom tax' in the UK in 2013 which decreed that anyone claiming housing benefit could have this reduced if their house was deemed to contain one or more unused rooms.
} 
homesickness (cf. Walsh 2006b) for these students in transition, concurring with the broad observation that meaningful possessions in domestic space can "(re)juvinate different parts of self” (Gorman-Murray 2008: 298) and that belongings may be used by students to place a veneer of homeliness upon their term-time accommodation (Kenyon 1999). This sense of homeliness was commonly associated with belongings which drew links to the familial home:

"I’m not like a "I need mummy and daddy with me everywhere" kind of a person but I like to have that sense of “this is my safe area”. It's nice to be able to go into my room when I've had a crap day at Uni [sic] or someone's done something and look round and there's a photo of my family or of my gran and granddad or my dog, it was nice. [...] I tried to make it my home away from home because I needed it, it made me happy to be like that” (Sophia, Y3).

"I brought photographs up from home in frames and put them around my room. And bedding was so important, having something colourful because the Uni [sic] rooms are so plain. Just like having your own stuff in there from your room gives it your own sense of style. It makes it a lot more homely and putting up those fairy lights and stuff” (Joanna, Y3).

Whilst we might read the extracts above along the lines of 'stability' in that the objects can be seen to offer a sense of familiarity and continuity, and appending statements such as "your own sense of style" and "my home away from home” suggest that personal reflection and comfort are key drivers of how rooms were laid out, it was also apparent, at a second level, that individuality and difference were at the same time a method of conformity. Although there is a long history of recognising how ostensibly 'private' homemaking practices are (re)shaped by broader social relationships and politics - particularly in relation to the 
ideologies of sexuality materialised in the nuclear family home (Gorman-Murray 2008) - we see how ideologies of what it is to be a student shape the material presentations of student rooms. Joanna's narrative in particular illustrates how decorating the room also served the function of moving away from the "plain room". To not have decoration, the interview responses across the research suggested, is not to participate in being a student (see Figure 3). Similarly, the dual public-private role of their room is intimated in Sophia's reference to "not needing mummy and daddy with me everywhere” - recognising that whilst she admits to enjoying the presence of these possessions she is acutely aware of their reception by others. Whilst she intends the room to be "nice" and "safe", these personal concerns are balanced in relation to those perceptions of her peers, with the decision over which belongings to include also an outward display to others - the relevance of which to student relations is expanded upon later in the paper. In these cases we see how room decoration facilitates not only the material expression of particular people and places, such as evidenced in the photographs of Sophia, but that the practice of decorating and homemaking itself reproduces a specific subject position of 'student'.

Just as we see that individual choice is shaped by a desire to conform with those around them, so too we see that their 'homemaking' practices in their student rooms are not performed in temporal isolation from their past experiences in the familial home. Holdsworth and Morgan (2005: 84) suggest, "home is something to be worked out, it is not an instantaneous creation” and for some it was evident that the practices of setting up their student rooms were shaped not only by themes of comfort, familiarity and conformity, but also as a more pragmatic response to restrictions imposed, often by parents, on the decoration of bedrooms in the familial home: 
“I’m not allowed to put pictures on the wall or anything [at home] as the blu-tack pulls the paint off and my parents are very like that” (Alice, Y2).

“My mum wouldn’t let me put my own stuff out. I wanted a lightshade to go on my globe and I wasn’t allowed to do that but here I can do it so I put that rectangle lampshade on my light, which was really nice. It feels less restrictive that back at home which is good. Whereas my mum is like "this is my house, you do as I say you do” kind of thing” (Rachel, Y1).

It has been suggested that whilst the home space may be intersectional - incorporating the lives of a number of household/family members (Hendon 2000) - it is commonly key individuals, often mothers (see Rose (2003) for a discussion of mothers' involvement in the arrangement of family photographs in the familial home), who take control of which items may be displayed. The presence of such domestic moralities is something which students may seek to break away from as they reach University. For these, the use (and very particular placement) of artefacts was not just a reminder of home, but was also a demonstration of being able to perform home differently. Such different performances of home were not just, the interviews revealed, as simple as pointing to the removal of parental surveillance, but also the ability to break from routines and structures of their familial home. Examples cited included the intervention of a parent coming to clean the room on a weekly basis, the need for the room to be 'tasteful' to accommodate a grandparent sleeping there during their visit and the presence of a younger sibling restricting the type of material (such as posters) that they could display. ${ }^{6}$ For these students their room at University allowed a less compromised and constrained form of self-expression than the 'possible selves' noted by Steele and Brown

\footnotetext{
${ }^{6}$ Although a more constrained ability for self-expression was noted across the sample here, it should be noted that not all students will have access to their own rooms in familial homes.
} 
(1995) as they disconnect not only from family members, but also the normative routines of the family home.

Linking together the ideas of both the influence of past home experiences and the presence of other students were the cases of Michael and Sophia, who spoke of the longer-term connections to the artefacts that they showed:

“I think I’ve always grown up with that teddy [points], I've always had that, it’s part of my experience and part of me it's always been with me. I’ve had that balancing Dragonfly that's on the corner of that cupboard and I've had that for years. It was up in halls, up last year and everyone’s known it, and knows it as part of me” (Michael, Y3).

"I was one of those sad people who brought everything I owned with me. I have my beanbag, my cuddly toys, my double duvet for my tiny little bed. I got given a plant, a lucky bamboo plant which I grew. It’s my bedroom duplicated on a small scale, I imitated it. [...] Ironically everyone loves it and most of the time people are in my room, watching TV in my room on a beanbag or wherever, it's kind of the second kitchen, I like it like that, it’s nice” (Sophia, Y3).

In both cases the response to homemaking at University was to recreate, often quite literally, the set of belongings they had at home with the response of Liam, in particular, illustrating how artefacts might serve to embody their biographical history. Whilst the literature on home is replete with references to how artefacts such as pictures may be used as reminders of the past, particularly among older people, both Michael and Sophia’s narratives hint at the role these artefacts might play in the present and the future. As Sophia's points suggest, her belongings also served as narrative prompts and points of connection with her housemates (see Figure 4). At the same time that belongings serve to story students' biographies, and thus 
act as a point of individuality and distinction, they also offer a point of connection to fellow students. As Tolia-Kelly (2006: 341) notes for diasporic homes their artefacts may be "sites of memorial to mobility itself” and the reference of Michael to "everyone knows it” and Sophia's to "it’s kind of the second kitchen” illustrate how their often very personal and individual belongings also serve to position them as 'not being from around here' (to borrow Holdsworth's (2009b) term) and create a sense of propinquity to be developed to other nonlocal students. Building on from this, the interviews revealed how belongings and their arrangement could also be used not just as a reminder of the past but also served as an important connection to what students wished to become in the future. So, the display of the dragon fly in the case of Michael represented his desire to travel and his specific interest in the tropics. Unlike other students who displayed pictures from gap years spent travelling which acted as a point of conversation generally, and a point of further connection to those areas specifically - it represented a desire for the future for Michael. Such belongings might be seen as an invitation to conversation, not based on a past experience per se, or an identity fully formed, but as something more open-ended, a future experience and identity which students wish to develop.

\section{A cumulative process}

Hinted at in the final points of the last section was how belongings relating to different time periods - such as those from childhood, those from adolescence and those collected whilst at University - coexist within student rooms. It was not, interviews revealed, a simple case of new artefacts - which embody new experiences and are part of the performance of new identities - replacing old ones, but that rooms became a site for their cumulative, layered identities which incorporated many facets of individuals’ student and non-student lives. The fluidity of this process was noted in participants' accounts, with the discussion of how they 
had initially made mistakes, and often returned home to collect or deposit belongings, a common focus:

“A couple of weeks in I went home and decided to bring my guitar home because I really missed it, I wasn’t going to bring it down because I couldn’t fit it in the car [...] but I don’t think I would have survived University without it” (Debbie, Y1).

"I use it [bedroom] as a sort of mini music studio. [...] I've got my piano up as well which is quite helpful. [...] I brought my piano down this year so I can actually practice with music. Because I find it hard to find an equal amount of time for coursework, incorporating music into my time can be quite difficult. But I never feel like it's a chore” (Richard, Y2).

At one level, the responses perhaps illustrate the students' lack of experience of residential moves - in the same way that Smith and Holt (2007) refer to students as 'apprentice gentrifiers', so too we might see them as apprentice relocators or apprentice homemakers. The first quote illustrates how the aforementioned process of belongings offering a point of connection to other students, becomes solidified as they move through their University life. Pictures with University friends, as well as artefacts such as mementos from Freshers' Week and first year activities serve as markers of connection and inclusion. ${ }^{7}$ Here, we see a shift in scale from the connection of not being around here, to a more active and intimate set of connections (re)shaping the belongings they have on display.

At a second level, the quotes from Debbie and Richard also illustrate how the anchor of home ${ }^{8}$ provides a space from which to trial, as students interchange belongings with those

\footnotetext{
${ }^{7}$ Freshers' week is a period at the beginning of the academic year where events are organised by Universities in order to welcome and orientate new students (might also be referred to as 'Orientation' or 'welcome' week).

${ }^{8}$ All of the interviewees reported returning home during the summer.
} 
from the familial home. In relation to previous work on homes we might see this interdependence (after Lahelma and Gordon 2008) as a more geographically stretched form depending less on parents for the physical space of the familial home or for daily emotional support per se, but a space from which buttress their new student lives. On the one hand there were very practical issues of how much 'stuff' could physically be brought to University, whilst on the other the narratives illustrate how the significance of belongings may be enhanced or rediscovered within the University context. Whilst University is often set within a discourse of transformation (Holdsworth 2009b; Wiborg 2004), such artefacts illustrated how pre-existing hobbies may be revisited or take on extra significance within the University context. For Debbie, it was only in shifting context from home to University that she realised the role music played in her life and her sense of wellbeing (Debbie was extremely pragmatic about the other belongings she chose to bring with her). Importantly, both quotes illustrate that their use of belongings cannot be categorised as just a way of recreating home or overcoming homesickness (Walsh 2006a), but were a method of performing a particular routine or activity less closely connected to their University identity.

Alongside this we see how, for second and third year students especially, the very particular spatial and temporal contexts of student life shapes the intermixing of artefacts associated with their student, pre-student and non-student identities, and illustrates a very particular way of 'doing home':

“I love my bedroom, I have everything I’ve ever wanted in there. At one point I even had a kettle because it was such a pain to get it from the kitchen. I love my room, I live and breathe in here. I study, watch films, TV, have friends round. It's my room, it’s my space” (Sophia, Y3).

"I kind of made it my own. I’ve got pictures around the house and my bits and 
bobs. I bought a cushion in first year which is on my bed and now has become like my seat. Yeah, it’s like me all over. I’ve got my scented candles, I like them, especially when I'm trying to work. I've got one for sleep and one for work. I’ve got my stereo which I play my own music on. Your room is yours, even if it’s empty it's got your stuff in it so it’s yours” (Lorna, Y3).

Spatially, the bounded space of the student room which, Sophia suggests, is at once a space of work, sleep, recreation and eating, means that identity management through artefacts is a complicated process for students. Creating an holistic sense of self through "diverse identity fragments” (Gorman-Murray, 2008, p.284) is concentrated into one location (cf. GormanMurray (2006) on the role of separate rooms such as the bedroom) and we see an intensification of the process of self-identification within student rooms. Sophia's reference to having 'friends around' to visit and Lorna's observation that 'your room is yours' suggests that the very fluid boundary of public-private which becomes rolled back in first year halls of residence might be redefined and redrawn as students move into private rented accommodation in years 2 and 3. Apparent within Sophia and Lorna's homemaking practices is that in parallel to materialising relationships and shared subjectivities through certain objects they at the same time use and arrange their material possessions in ways that facilitate their individuality within this shared living space.

Related to the processes of self-identification we see the importance of temporality - that is, how the short-term and finite nature of being a student (and the even shorter-term nature of their residences across the three years) has implications for how, and which, material possessions are used within the material autobiography (after Hecht, 2001) of the home. Most notable was how it was often not just durable artefacts - purposely designed as momentos (e.g. holiday souvenirs) - but also more ostensibly ‘throwaway’ or ephemeral artefacts such 
as such as flyers, concert tickets or nightclub wristbands that have the potential to embody particular memories and act as reflexive representations of a student's identity, or the way they may narrate this identity. Alongside this we see how artefacts bought whilst at University, rather than those brought from home, start to become some of the most significant possessions discussed in interview. So for Lorna her candles and her cushion which is 'me all over' - represent not only an emerging and evolving sense of individual taste, but also a particular way of using their 'home' space and become tied to particular routines which bring together their social life and their identity as a student/learner.

\section{A finite process: 'self-archiving'}

As suggested earlier in the paper, students' domestic experiences differ from those of diasporic communities, for example, in that their [re]location to University accommodation is a time limited process ${ }^{9}$. The consciously finite nature of this University experience has important consequences for the accumulation of belongings. Perhaps as would be expected, there was ample evidence from those third year students spoken to of the pragmatic processes of sorting and discarding observed by Walsh (2006b) in her discussion of British expatriates living in Dubai. However, rather than simply throwing things away, the participants spoke of how belongings were ordered, and reordered according to their significance during the degree:

"Some of the things I have are like the odd flyer and handouts you get [...] and gig tickets from when I've been out in Portsmouth. [...] I look at them quite regularly, especially now as I'm coming to the end of Uni [sic] so I'm reflecting back on the

\footnotetext{
${ }^{9}$ There is, however, a suggestion within the student geographies literature that students may stay on in University towns to live after graduation and attempt to extend the student life (Hubbard 2009).
} 
process. [...] It's nice to have things that remind me of specific points during that time” (Lisa, Y3).

As Lorimer (2007: 58) has eloquently noted in relation to our ridding of personal artefacts: “once treasured, now mothballed, each item opens worm-hole into others’ worlds” and relating to Gorman-Murray’s (2008) observation that belongings may comprise a range of connections (family, sexuality, travels etc.) we see how, for some, such connections-throughbelongings are spatially and temporally bounded. Although the belongings Lisa referred to were associated within significant events and 'happy times' at University much of their value was, her wider interview suggested, born out of their active role whilst she was with still with her friends. Following on from the paper's earlier observation that personal belongings might be important for generating connections, the example here illustrates how some artefacts might become meaningless without these accompanying narratives, or their relevance being continually revisited. So, the meaning of the belongings is held together by the accompanying stories of this place and once one aspect of this triumvirate of place, friends and objects is lost - their immediate value may be diminished. The recognition of the finite nature of their student living was also observed by Michael:

“We're only going to be here for ten months so I'm very conscious that this is not a permanent house. Last year we were still trying keep living our first year whereas now we've calmed down. Last year I used to have my climbing t-shirts all up on the wall and I was reminiscing of first year whereas this year I didn't want to feel like I was reminiscing so much. This year is so different to last year being involved in sailing, I didn’t want to be looking back, I wanted a fresh start, to have fresh memories distinct from first and second year. It was nice having pictures up but I felt I was constantly looking back whereas this year I want to be looking forward. [...] I 
think I will still have pictures up of my whole experience collectively but not in the sense of wallowing in it and having a shrine to my Uni [sic] years (Michael, Y3).

The theme of the active role of objects apparent in the interview of Lisa was also seen in Michael's discussion, but here attention was on how these had changed through the course of the degree. What in his first year were used as points of discussion and a way of building bonds to other people become less significant towards the end of the degree and, moreover, they become removed from view (and perhaps, therefore, as conversation pieces) in order that the memories they embody may remain undisturbed. What we see is something counter to the commonly received wisdom on artefacts being used to keep memories in the present. For this, and several other respondents, it was a set of experiences that they do not wish to be frequently rehearsed or re-narrated.

This theme of re-evaluating the emotional worth of objects was also extended on in the discussion of the rooms of Lucy and Lyndsey:

“Certainly in halls my walls were absolutely covered in photos, now I only have a few up. I think it was a habit I started doing in halls, putting up photos. [...] I had them everywhere so the ones that were around my sink I would look at more regularly than others and it was quite nice if I was bored I would look around at some of the ones I didn't really notice so often. [Now] most of them are in a folder in the bottom of a drawer somewhere, I'm not actually sure whether they're here or at home at the moment” (Lucy, Y2).

“I used to have so many things stuck up on my wall and now I have a drawer and it's just under my printer and it's full of letters. I’ve got lots of memories hidden away in there. Like when my parents came to visit we took a photo in the fountain over there [in Commercial Road] which was nice, and when they came in the winter it was 
frozen and in the summer it's so beautiful, so I had those pictures of before and after.” (Lyndsey, Y3).

These cases offer similarities to those explored by Walsh (2006b) in which lives are distilled down into important objects, but stops short of the finality of items being disposed of in moving on to the next phase of life (e.g. Cherrier and Murray 2007). Here, instead, some items become re-placed - not being out on display, but remaining easily available to respondents to revisit as Lyndsey suggests. However, in this instance, rather than reacting against the conditions of parents or landlords, the participants were discussing how their artefacts began to coexist with one another, rather than attempting to completely break away from their non-student identities. The collection together of these items and their storage is an important act chosen instead of disposal. There was not a desire to be rid of the artefacts and the memories, people and places they serve to hold together, but a wish to selectively [re]experience these. Such observations offer important insights for both our understandings of homemaking generally and for students specifically. Such (re)placing of personal items can be seen as an aspect of homemaking as a 'boundary making’ process (after Power, 2009). Here we see that such boundaries are not limited to (dis)connection to other people or places but also to a consideration of how past memories will be (re)visited. Whilst such boundary making is often talked of, in dichotomous terms, along the lines of either inclusion through display or exclusion through disposal (see Gregson et al. 2007b), our observations here show a more open-ended process whereby the careful storage of personal belongings protects their mimetic value and affords their owners the opportunity to revisit their experiences at their own discretion. In relation to students specifically, such examples of self-archiving extend our understanding of the dynamic and fluid relationships these interview participants had between their family home and term-time accommodation as their status as 'being' students adapted and changed during their degree. 


\section{Conclusion}

Through a focus on students and their residences, this paper has added to understandings of place-making and home and has contributed to the recent scholarship which has sought a consideration of 'home' beyond a bounded geographical location and as something which can be more transitory, multi-sited and open ended. The paper has highlighted the important temporalities of students' experiences of home and 'homemaking'. The necessarily finite nature of being a student shapes how homes, and bedrooms especially, are materially organised and utilised. Students are selective in what belongings and artefacts they choose to take to University and have on display - and whilst this process, perhaps predictably, involves a sense of coherence and continuity as possessions are brought from pre-University (most commonly familial) homes it also a selective process where conscious disconnection is sought from particular sets of routines and normative assumptions. Such a filtering of previous possessions and their integration and accumulation alongside new possessions is a far from linear process, with the value and significance of objects reconsidered and revisited through the course of students' University experience. Moreover, the utilisation of personal possessions within students' homemaking practices are not simply about solidifying preexisting identities, but can also have a clear future orientation. Here our observations contribute to the call to move beyond seeing objects of the home as entirely connecting to the past (cf. Blunt and Dowling, 2006), but instead recognising that they may enable conscious display of the future subject positions individuals may wish to inhabit, and people to whom they may wish to connect.

The paper has seen that how rooms are utilised and furnished is important to identity expression and the performance of particular subject positions. The observations here mirror previous work which notes that transition, particularly away from the surveillance in the 
family home, can lead to a sense of reinvention. It extends this, however, by noting that this relational process is not just limited to family homes but also to the students with whom they now reside, with very specific ideals of how student rooms should be adorned developed iteratively within specific contexts such as particular halls of residence. Here, the evidence from this paper adds to the emerging research which has considered how homes and objects facilitate shared subjectivities (e.g. Gorman-Murray 2006; Morrison 2013) and deepens the observation that possessions may be used to materialise relationships whilst also noting that at the same time personal belongings might be used to maintain some sense of individuality, and demarcate spaces of privacy, within these shared living spaces. Furthermore, our observations show that when 'home' is multi-sited (between 'term time' and 'permanent' addresses for those here) it can offer productive space(s) for trialling particular subject positions and can allow identity expressions to be consciously placed. Alternating between spaces can allow particular performances, and particular belongings associated with certain identities, to be played out with a gradual prioritising, over time, of one of these spaces. As their time at University comes to an end and moves, again, to a single location - either back to the familial home or to a permanent new address - it is their belongings, through careful compartmentalisation in the form (re)placing and archiving, which allow them to connect with aspects of previous identities as they become selectively revisited, performed and retold. Such notions of compartmentalisation would appear to offer an alternative perspective on the nature of the transition through University to suggest that, rather than being linear, or even cyclical, these students' domestic experiences highlight the potential for it to be curved, with students' sense of place intensifying as they begin to settle into University life, and then gradually becoming compartmentalised as decreasing in intensity as they consider become 'post-students' once the degree is completed. Using the evidence from this study - albeit recognising that elements of this are particular to the UK and University context of our study 
- this curve can be demonstrated as follows. The students entered the transitional period of University, constructing their student identities through learning and experimentation and through maintaining a discursive relationship with home through the use of mimetic objects. The students' identities then increased in intensity over the middle part of the degree through confidence and maturation and a gradual honing of tastes and desires which cumulatively established a more individualised student identity. Finally, the need for a student identity gradually diminished in the latter stages of the degree as the students prepared to leave University and commence their 'post' student lives. Whilst our observations here relate to a specific sample of University students, these notions or trialling, archiving and revisiting arguably have a wider relevance given the predominant trend towards younger people living in the familial home for longer periods of their lives.

Although we have seen in this paper, in line with studies on diasporic and transnational communities, that possessions may be (re)placed from previous homes into new homes and serve one or a combination of therapeutic, memory, connective and signifying roles, our evidence from final year students showed how some objects are less easily moved and able to fill these functions. The reasons for this inability are twofold and have relevance beyond the case of the students considered here for how we might understand homemaking. First, the memory or sign value of certain possessions is reduced when their meaning is not continually revisited in a particular place by the specific people who helped give them meaning in the first place. So, unlike photographs which offer a visual reminder of people or places, more ephemeral objects may lose their significance when taken out of specific contexts. In taking on board the observations from recent work which show the role of objects in the home perform not just individual work but shape shared subjectivities (e.g. Morrison 2013), our evidence here suggests that this is a two-way process and it is only in the context of performing these shared subjectivities that the objects may hold full meaning to their owner. 
A second reason observed for not (re)placing objects in new homes is a desire to not revisit the memories they embody. Previous research has shown how possessions and objects may become re-storied and brought into the present (Hockey et al 2005) and our case here suggests that this may not always be seen as a wholly positive process and individuals may avoid their display in order that the memories and connections they embody do not become disturbed.

In considering the wider application of our findings beyond the empirical focus on students here, critical reflection is needed on the nature and scope of the study. Methodologically, the question arises of whether rooms become 'stage managed', for the purposes of the interviewer, by interviewees. Whilst we are mindful of this possibility, and would encourage the deployment of more longer-term ethnographic engagement to get at the lived experiences of student spaces in future research, we would argue that any impression management is itself an interesting source of data and understanding how students wish to present their home and possessions is equally as important as how they live with them day to day. With regard to the specific sample of students, it should be recognised that whilst going away to University is relatively common in the UK context (e.g. Smith and Sage (2014) noted that 11.1 per cent of all 16-24-year-olds moved across a regional border in 2008), it is less common in other countries (e.g. Fincher and Shaw (2009) emphasise the particularity of intra-national mobility to the UK HE experience). However, while domestic students (in an international context) are far less likely to leave home for University, the increasing globalisation of international HE (Madge et al, 2014) opens up opportunities to explore the residential experiences of students living abroad.

\section{References}


Amole, D. (2009) Residential satisfaction in students' housing, Journal of Environmental Psychology 29: 76-85.

Andersson, J. Sadgrove, J. and Valentine, G. (2012) Consuming campus: geographies of encounter at a British University. Social \& Cultural Geography 13: 501-515.

Barthes, R. (1993) A Barthes reader, Random House.

Blunt, A. (2005) Cultural geography: cultural geographies of home, Progress in Human Geography 29: 505-515.

Blunt, A., and Dowling, R. (2006). Home. New York: Routledge.

Blunt, A. and Varley, A. (2004) Introduction: geographies of home, Cultural Geographies, 11: 3-6.

Borg, M., Sells, D., Topor, A., Mezzina, R., Marin, I., and Davidson, L. (2005). What makes a house a home: The role of material resources in recovery from severe mental illness. American Journal of Psychiatric Rehabilitation, 8(3), 243-256.

Brickell, K. (2012) 'Mapping’ and ‘doing’ critical geographies of home, Progress in Human Geography 36: 225-244.

Brooks, R. (2003b) Young people’s higher education choices: the role of family and friends, British Journal of Sociology of Education 24: 283-297.

Chatterton, P. (1999) University students and city centres: the formation of exclusive geographies: the case of Bristol, UK, Geoforum 30: 117-133.

Cherrier, H., and Murray, J.B. (2007) Reflexive dispossession and the self: constructing a processual theory of identity, Consumption Markets \& Culture 10: 1-29. 
Chow, K. and Healey, M. (2008) Place attachment and place identity: first year undergraduates making the transition from home to University, Journal of Environmental Psychology 28: 362-372.

Christie, H. (2007). Higher education and spatial (im)mobility: non-traditional students and living at home, Environment and Planning A 39: 2445-2463.

Christie, H. Munro. M. and Rettig, H. (2002) Accommodating students, Journal of Youth Studies 5: 209-235.

Duke-Williams, O. (2009) The geographies of student migration in the UK, Environment and Planning A 41: 1-23.

Dunn, K. (2010). Embodied transnationalism: bodies in transnational spaces. Population, Space and Place 16: 1-9.

Fidzani, L.C., and Read, M.A. (2012) Bedroom personalization by urban adolescents in Botswana: developing place attachment, Children Youth and Environments 22: 66-92.

Fincher, R. and Shaw, K. (2009) The unintended segregation of transitional students in central Melbourne, Environment and Planning A 41: 1884-1902.

Goffman, E. (1959). The Presentation of Self in Everyday Life, New York: Doubleday. Gorman-Murray, A. (2006) Homeboys: uses of home by gay Australian men, Social \& Cultural Geography 7: 53-69.

Gorman-Murray, A. (2007) Contesting domestic ideals: queering the Australian home, Australian Geographer 38: 195-213. 
Gorman-Murray, A. (2008) Reconciling self: gay men and lesbians using domestic materiality for identity management, Social and Cultural Geography 9: 283-301.

Gregson, N., Metcalfe, A., and Crewe, L. (2007a) Identity, mobility and the throwaway society, Environment and planning D: Society and Space 25: 682-700.

Gregson, N., Metcalfe, A., Crewe, L. (2007b) Moving things along: the conduits and practices of divestment in consumption, Transactions of the Institute of British Geographers 32: 187-200.

Hecht, A. (2001) Home sweet home: tangible memories of an uprooted childhood, in Miller, D. (ed.) Home Possessions: Material Culture Behind Closed Doors. Oxford: Berg, pp.123145.

Hendon, J.A. (2000) Having and holding: Storage, memory, knowledge, and social relations, American Anthropologist 102: 42-53.

Hockey

Holdsworth, C. (2009b) 'Going away to Uni’: mobility, modernity, and independence of English higher education students, Environment and Planning A 41: 1849-1864.

Holdsworth, C. and Morgan, D. (2005) Transitions in context: leaving home, independence and adulthood. Maidenhead: Open University Press.

Hollows, J. (2008) Domestic cultures. Maidenhead: McGraw-Hill International.

Holton, M. and Riley, M. (2013) Student geographies: exploring the diverse geographies of students and higher education, Geography Compass 7: 61-74. 
Holton, M., and Riley M. (2014) Talking on the move: place-based interviewing with undergraduate students, Area 46: 59-65.

Housley, W., and Smith, R.J. (2010) Innovation and reduction in contemporary qualitative methods: the case of conceptual coupling, activity-type pairs and auto-ethnography, Sociological Research Online 15: 9.

Hubbard, P. (2009) Geographies of studentification and purpose-built student accommodation: leading separate lives? Environment and Planning A 41: 1903-1923.

Hurdley, R. (2006) Dismantling mantelpieces: Narrating identities and materializing culture in the home, Sociology 40: 717-733.

Kenyon, E.L. (1999) A home from home: students' transitional experiences of home, in Chapman, T., and Hockney, J. (eds.) Ideal homes? Social change and domestic life. London: Routledge, pp.84-95.

Lahelma, E. and Gordon, T. (2003) Home as a physical, social and mental space: young people’s reflections on leaving home, Journal of Youth Studies 6: 377-390.

Lahelma, E. and Gordon, T. (2008) Resources and (in(ter))dependence: young people’s reflections on parents, Young 16: 209-226.

Larson, R. (1995) Secrets in the bedroom: adolescents' private use of media, Journal of Youth and Adolescence 24: 535-550.

Larson, R.W. (1997) The emergence of solitude as a constructive domain of experience in early adolescence, Child Development 68: 80-93. 
Lorimer, H. (2007) Songs from before - shaping conditions for appreciative listening, in Gagen, E., Lorimer, H. and Vasudevan, A., (eds.) Practising the archive: reflections on method and practice in historical geography. Glasgow: Historical and Cultural Geography Research Group, pp.57-74.

Madge, C., Raghuram, P., and Noxolo, P. (2014) Conceptualizing international education From international student to international study, Progress in Human Geography DOI:0309132514526442.

Marcoux, J.S. (2001). The Refurbishment of Memory, in Miller, D. (ed.) Home Possessions: Material Culture Behind Closed Doors. Oxford: Berg, pp.69-86.

Miller, D. (1987) Material Culture and Mass Consumption. Oxford: Blackwell. Morrison, C.A. (2013) Homemaking in New Zealand: thinking through the mutually constitutive relationship between domestic material objects, heterosexuality and home, Gender, Place \& Culture, 20(4), 413-431.

Peters, K. (2011) Negotiating the 'place' and 'placement' of banal tourist souvenirs in the home, Tourism Geographies: An International Journal of Tourism Space, Place and Environment 13: 234-256.

Power, E.R. (2009) Border-processes and homemaking: encounters with possums in suburban Australian homes, Cultural Geographies 16:29-54.

Reay, D. Crozier, G. and Clayton, J. (2010) 'Fitting in' or 'standing out': working-class students in UK higher education, British Educational Research Journal 36: 107-124.

Riley, M. (2010) Emplacing the Research Encounter: Exploring Farm Life Histories, Qualitative Inquiry 16: 651-662. 
Rose, G. (2003) Family photographs and domestic spacings: a case study, Transactions of the Institute of British Geographers 28: 5-18.

Rose, G. (2007) Visual methodologies: an introduction to the interpretation of visual materials ( $2^{\text {nd }}$ ed). London: SAGE.

Rowles, G.D., and Chaudhury, H. (2005). Home and identity in late life international perspectives. New York: Springer

Rugg, J., Ford, J., and Burrows, R. (2004) Housing advantage?: the role of student renting in the constitution of housing biographies in the United Kingdom, Journal of Youth Studies 7: 19-34.

Silver, H. (2004) ‘Residence’ and ‘accommodation’ in higher education: abandoning a tradition, Journal of Educational Administration and History 36: 123-133.

Smith, D.P. (2009) 'Student geographies’, urban restructuring, and the expansion of higher education, Environment and Planning A 41: 1795-1804.

Smith, D.P. and Holt, L. (2007) Studentification and 'apprentice' gentrifiers within Britain's provincial towns and cities: the meaning of gentrification, Environment and Planning A 39: $142-161$.

Smith, D.P., and Hubbard, P. (2014) The segregation of educated youth and dynamic geographies of studentification, Area 46: 92-100.

Smith, D.P., Rérat, P., and Sage, J. (2014) Youth migration and spaces of education, Children's Geographies 12: 1-8. 
Smith, D.P., and Sage, J. (2014) The regional migration of young adults in England and Wales (2002-2008): a ‘conveyor-belt’ of population redistribution? Children's Geographies 12: $102-117$.

Steele, J.R., and Brown, J.D. (1995) Adolescent room culture: Studying media in the context of everyday life, Journal of youth and adolescence 24: 551-576.

Thomsen, J. (2007) Home experiences in student housing: about institutional character and temporary homes, Journal of Youth Studies 10: 577-596.

Tolia-Kelly, D.P. (2004) Materializing post-colonial geographies: examining the textural landscapes of migration in the South Asian home, Geoforum 35: 675-688.

Tolia-Kelly, D.P. (2006) Mobility/stability: British Asian cultures of landscape and Englishness', Environment and planning A 38: 341.

Waitt, G., and Gorman-Murray, A. (2011) “It’s about time you came out”: sexualities, mobility and home, Antipode 43: 1380-1403.

Walsh, K. (2006a) British expatriate belongings: mobile homes and transnational homing. Home Cultures 3: 123-144.

Walsh, K. (2006b) 'Dad says I’m tied to a shooting star!': Grounding (research on) British expatriate belonging, Area 38: 268-278.

Wiborg, A. (2004) Place, nature and migration: Students' attachment to their rural home places, Sociologia ruralis 44: 416-432.

Woodward, I. (2001). Domestic Objects and the Taste Epiphany A Resource for Consumption Methodology, Journal of Material Culture, 6(2), 115-136. 
Young, I. (2005) House and home: Feminist variations on a theme, in Young I.M. (ed) On female body experience: 'Throwing like a girl’ and other essays, New York: Oxford University Press, pp.123-54.

Gorman-Murray, A., 2006. Homeboys: uses of home by gay Australian men. Soc Cult Geogr 7, 53-69.

Gorman-Murray, A., 2008. Reconciling self: gay men and lesbians using domestic materiality for identity management. Social and Cultural Geography 9, 283.

Hecht, A., 2001. Home sweet home: tangible memories of an uprooted childhood, in: Miller, D. (Ed.), Home Possessions: Material Culture Behind Closed Doors. Berg, Oxford, pp. 123145.

Hockey, J., Penhale, B., Sibley, D., 2005. Environments of memory: Home Space, Later Life and Grief, in: Bondi, L., Davidson, J., Smith, M. (Eds.), Emotional Geographies. Ashgate Publishing, Aldershot, pp. 135-146.

Power, E.R., 2009. Border-processes and homemaking: encounters with possums in suburban Australian homes. Cultural Geographies 16, 29-54. 
Table 1: Demographic profile of the participants of the walking interviews (source: authors' interview data).

\begin{tabular}{|c|c|c|c|c|c|c|c|c|c|}
\hline & \multirow{2}{*}{ Year } & \multirow{2}{*}{ Gender } & \multirow{2}{*}{ Age } & \multirow{2}{*}{ Ethnicity } & \multirow{2}{*}{ Nationality } & \multicolumn{3}{|c|}{$\begin{array}{l}\text { Term-time residential } \\
\text { circumstances }\end{array}$} & \multirow{2}{*}{ Home region } \\
\hline & & & & & & Year 1 & Year 2 & Year 3 & \\
\hline Michael & 3 & Male & -21 & White & British & Hall & Rented & Rented & Kent \\
\hline Nicola & 1 & Female & -21 & White & British & Rented & - & - & Bucks \\
\hline Eathan & 1 & Male & -21 & White & Russian & Rented & - & - & Hampshire \\
\hline Gary & 2 & Male & -21 & White & British & Hall & Rented & - & Surrey \\
\hline Lucy & 2 & Female & -21 & White & British & Hall & Rented & - & Berks \\
\hline Joanna & 3 & Female & -21 & White & British & Hall & Rented & Rented & Surrey \\
\hline Colin & 1 & Male & -21 & White & British & Hall & - & - & Gwynedd \\
\hline Jonny & 1 & Male & -21 & White & British & Hall & - & - & Surrey \\
\hline Richard & 2 & Male & -21 & White & British & Rented & Rented & - & Devon \\
\hline Kirsty & 2 & Female & -21 & White & British & Rented & Rented & - & Lancashire \\
\hline Michelle & 3 & Female & -21 & White & British & Hall & Rented & Rented & $\begin{array}{l}\text { Greater } \\
\text { London }\end{array}$ \\
\hline Robert & 1 & Male & $22+$ & White & Romanian & Rented & - & - & Romania \\
\hline Lorna & 3 & Female & $22+$ & Black & British & Rented & Rented & Rented & $\begin{array}{l}\text { Greater } \\
\text { London }\end{array}$ \\
\hline Kathy & 2 & Female & -21 & White & British & Hall & Rented & - & Devon \\
\hline Sophia & 3 & Female & $22+$ & White & British & Hall & Rented & Rented & Hampshire \\
\hline Simon & 1 & Male & -21 & White & British & Rented & - & - & Hampshire \\
\hline Debbie & 1 & Female & -21 & White & British & Rented & - & - & Kent \\
\hline Zoe & 3 & Female & -21 & White & British & Rented & Rented & Rented & Surrey \\
\hline Suzie & 1 & Female & -21 & White & British & Rented & - & - & Wiltshire \\
\hline Rachel & 1 & Female & -21 & Black & British & Rented & - & - & $\begin{array}{l}\text { Greater } \\
\text { London }\end{array}$ \\
\hline Lyndsey & 3 & Female & $22+$ & Asian & Malaysian & Halls & Rented & Rented & Malaysia \\
\hline
\end{tabular}

